\title{
Degree of Conversion of Etch-and-Rinse and Self-etch Adhesives Light-cured Using QTH or LED
}

\author{
AL Faria-e-Silva $\bullet$ AF Lima $\bullet$ RR Moraes \\ E Piva • LR Martins
}

\section{Clinical Relevance}

The effect of QTH and LED curing lights on the degree of conversion of bonding agents is material dependent.

\section{SUMMARY}

In the current study, the degree of conversion (DC) of bonding agents photoactivated using QTH or LED light-curing units (LCUs) was eval-

\footnotetext{
*André Luis Faria-e-Silva, DDS, MS, PhD, professor, Department of Dentistry, School of Dentistry, Federal University of Sergipe, Aracaju, SE, Brazil

Adriano F Lima, DDS, MS, PhD student, Department of Restorative Dentistry, Piracicaba Dental School, State University of Campinas, SP, Brazil

Rafael R Moraes, DDS, MS, PhD, professor, Department of Restorative Dentistry, School of Dentistry, Federal University of Pelotas, RS, Brazil

Evandro Piva, DDS, MS, PhD, professor, Department of Restorative Dentistry, School of Dentistry, Federal University of Pelotas, RS, Brazil

Luis R Martins, DDS, MS, PhD, professor, Department of Restorative Dentistry, Piracicaba Dental School, State University of Campinas, SP, Brazil

* Reprint request: Rua Cláudio Batista S/N-Bairro Sanatório, Aracaju, SE 49060-100, Brazil; e-mail: andrelfsilva@hotmail.com DOI: $10.2341 / 10-066-\mathrm{L}$
}

uated by Fourier Transform infrared spectroscopy with an attenuated total reflectance (ATR) device. Four LCUs were evaluated: one QTH (Optilux 501; Demetron Kerr) and three LEDs: Radii Cal (SDI), Elipar FreeLight 2 (3M ESPE) and Bluephase (Ivoclar Vivadent). Two etch-and-rinse (Scotchbond Multi-PurposeSBMP and Single Bond 2-SB2) and two self-etch adhesives (Clearfil SE Bond-CSE, and Clearfil $\mathbf{S}^{3}$ Bond-CS3) were tested. For SBMP and CSE, the primer was not used. The irradiance and spectral emission of the LCUs were obtained with a radiometer and spectrometer. The materials were placed onto the ATR cell as thin films, the solvent was evaporated (when necessary) and photoactivation was carried out for 20 seconds. The DC (\%) was evaluated after five minutes $(n=5)$. The data were statistically analyzed $(p<0.05)$. The irradiance for Optilux, Radii, FreeLight 2 and Bluephase was 760, 600, 1000 and $1100 \mathrm{~mW} . \mathrm{cm}^{-2}$, respectively. The wavelength of emission for Optilux was between 375 and 520 nm (peak at $496 \mathrm{~nm}$ ), while for Radii, it was 
between 420 and $520 \mathrm{~nm}$ (peak at $467 \mathrm{~nm}$ ). Freelight 2 presented an emission spectrum between 415 and $520 \mathrm{~nm}$, and for Bluephase, it was between 410 and $530 \mathrm{~nm}$, both having a peak at $454 \mathrm{~nm}$. SB2 generally showed higher DC compared with the other bonding agents. When cured using the QTH unit, the DC results were SB2=CS3 $>$ CSE $>$ SBMP; for all LEDs, the DC results showed SB2>CSE $>$ SBMP>CS3. For SB2, the highest DC was observed when the material was cured with Radii, while there were no significant differences among the other LCUs. CSE and CS3 showed higher DC when cured using the QTH unit, but similar results were observed among the LEDs. For SBMP, no significant differences among the LCUs were detected. In conclusion, the combination bonding agent vs curing unit had a significant effect on DC, mainly for the self-etch adhesives.

\section{INTRODUCTION}

The impact of strong adhesive bonds to dental hard tissues in the long-term clinical performance of composite restorations is still controversial. Several factors may affect longevity of the bonds, including the nature of the bonding agent and proper polymerization of the material. In vitro studies have indicated a good relationship between the degree of conversion (DC) and the mechanical properties of the adhesive with the strength of bonding to tooth tissues. ${ }^{1-3} \mathrm{~A}$ high DC may also reduce permeability at the bonding assembly, ${ }^{4}$ increasing the resistance to degradation..$^{5-6}$ Incomplete polymerization of adhesive monomers has been speculated as one of the reasons for the occurrence of nanoleakage. ${ }^{6}$

Dental adhesive agents contain (di)methacrylates that polymerize under irradiation with visible light. ${ }^{7}$ Camphorquinone (CQ) is the most widely used photosensitizer in light-cured dental materials, with an absorption peak at $468 \mathrm{~nm} .{ }^{8}$ For many years, quartztungsten-halogen (QTH) bulbs have been used as the main dental light-curing unit (LCU) for photopolymer- ization. These LCUs generate a relatively broad spectra of wavelengths, usually between 370 and $520 \mathrm{~nm}^{9}$ This wide spectrum embraces the absorption range of most photoinitiators used in adhesive systems. ${ }^{10-11}$ However, some factors may compromise the performance of QTH units, such as fluctuation in the line voltage, long-term degradation of the bulb and filter, contamination of the light guide, damage to the fiber-optic bundle and bulb overheating within the unit. ${ }^{12-13}$

On the other hand, the use of light-emitting diodes (LEDs) is increasingly popular among clinicians. LEDs consume little power and do not require filters to produce blue light. ${ }^{12,14}$ The semiconductors used for light emission, instead of the hot metal filaments in QTH bulbs, generate less internal heat and undergo little degradation over time. ${ }^{14}$ The main difference in the emission radiation is the narrower spectrum of wavelengths of the LEDs, usually centered at $470 \mathrm{~nm} .^{14}$ Investigators are still evaluating the effectiveness of LED technology for the photopolymerization of dental composites. ${ }^{15-16}$ However, adhesives usually present different comonomers as compared with resin composites, and they may also present organic solvents, which can affect polymerization. Despite these differences, the effect of LCUs on the DC of adhesive systems has seldom been evaluated. ${ }^{7,17}$

The current study evaluated the effect of one QTH and three LED LCUs on the DC of four commercial adhesives systems. The null-hypothesis tested was that the type of LCU would not impact the DC of the different systems.

\section{METHODS AND MATERIALS}

Four commercially available, light-cured adhesives systems were tested: Scotchbond Multi-Purpose (SBMP, 3M ESPE, St Paul, MN, USA), Single Bond 2 (SB2, 3M ESPE), Clearfil SE Bond (CSE, Kuraray Co, Ltd, Osaka, Japan) and Clearfil $\mathrm{S}^{3}$ Bond (CS3, Kuraray Co, Ltd). Classification, manufacturer and composition of all the materials are listed in Table 1. The DC of the bonding agents was measured using

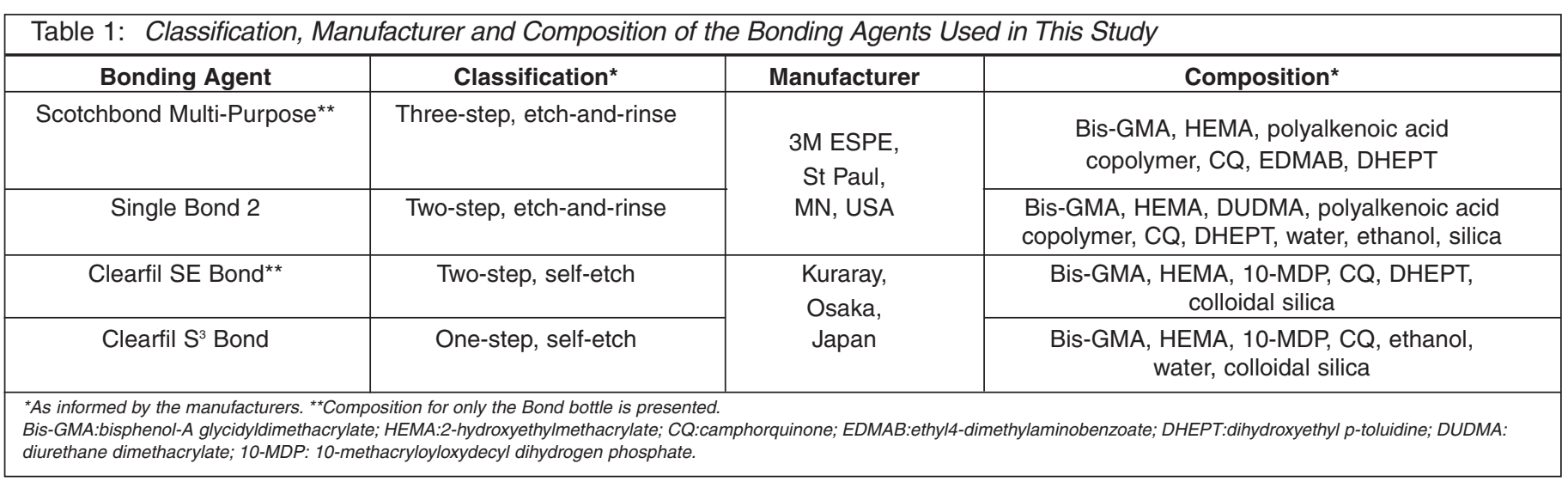


Fourier Transform mid-infrared spectroscopy (Prestige21; Shimadzu, Tokyo, Japan), equipped with an attenuated total reflectance (ATR) device. The ATR device is composed of a horizontal ZnSe crystal, with a $45^{\circ}$ mirror angle (Pike Technologies, Madison, WI, USA). Constant volume of the adhesive resin was placed on the horizontal face of the ATR cell, where total internal reflection occurs, as previously described. ${ }^{18}$ For SBMP and CSE, only the bond agent was tested, that is, the primer bottle was not used.

A support was coupled to the spectrometer to hold the LCU and standardize a $5-\mathrm{mm}$ distance between the light guide tip and material. Four LCUs were evaluated: one QTH (Optilux 501; Demetron Kerr, Orange, CA, USA) and three LEDs: Radii Cal (SDI, Bayswater, Victoria, Australia), Elipar FreeLight 2 (3M ESPE) and Bluephase (Ivoclar Vivadent, Schaan, Liechtenstein). The irradiance of each LCU was measured with a calibrated power meter (Ophir Optronics, Jerusalem, Israel), and the spectral distribution was analyzed using a computer-controlled spectrometer (USB2000; Ocean Optics, Dunedin, FL, USA). For the solvated adhesives SB2 and CS3, the solvent was evaporated for five seconds using a low-pressure air stream. The diameter of the specimens was restricted to match the diameter of the light guide. Before photoactivation, a Mylar strip was placed over the adhesive to avoid inhibition of the polymerization by oxygen. The resulting thickness of the specimen was $\sim 20 \mu \mathrm{m}$.

A preliminary reading for the unpolymerized material was taken under the following conditions: 32 scans co-addition, $1900-1400 \mathrm{~cm}^{-1}$ frequency range, $4 \mathrm{~cm}^{-1}$ resolution, Happ-Genzel apodization and $2.8 \mathrm{~mm} \cdot \mathrm{s}^{-1}$ mirror speed. Photoactivation was then carried out for 20 seconds. Although differences in irradiance among the LCUs generated unequal radiant exposures, the photoactivation time was kept constant to better simulate clinical conditions. The spectrum of the cured specimens was obtained five minutes after light-activation. The DC (\%) was evaluated in the absorbance mode using a baseline technique ${ }^{19}$ considering the intensity of $\mathrm{C}=\mathrm{C}$ stretching vibration (peak height) at $1635 \mathrm{~cm}^{-1}$ and, as an internal standard, using the symmetric ring stretching at $1608 \mathrm{~cm}^{-1}$, as previously described. ${ }^{18}$ Five specimens were tested for each group. The data were submitted to two-way ANOVA (bonding agent $v s$ LCU).

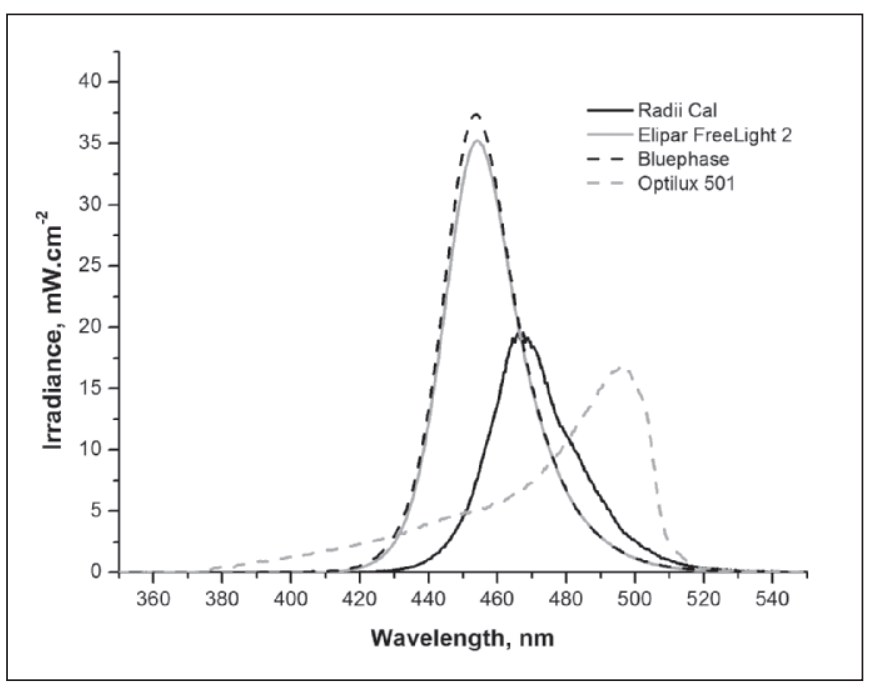

Figure 1. Light spectrum profiles emitted by the LCUs. The wavelength of emission for Optilux 501 was between 375 and $520 \mathrm{~nm}$ (peak at 496 $\mathrm{nm}$ ), while for Radii Cal, it was between 420 and $520 \mathrm{~nm}$ (peak at 467 nm). Elipar Freelight 2 presented an emission spectrum of between 415 and $520 \mathrm{~nm}$, and Bluephase presented an emission spectrum of between 410 and $530 \mathrm{~nm}$, both having a peak at $454 \mathrm{~nm}$.

All pairwise multiple comparison procedures were performed by the Student-Newman-Keuls' method $(p<0.05)$.

\section{RESULTS}

\section{Characterization of the LCUs}

The irradiance measured for Oplitux 501, Radii Cal, Elipar FreeLight 2 and Bluephase were 760, 600, 1000 and $1100 \mathrm{~mW} . \mathrm{cm}^{-2}$, respectively. The light spectrum profiles emitted by the LCUs are shown in Figure 1. The wavelength of emission for QTH Optilux 501 was between 375 and $520 \mathrm{~nm}$, with an emission peak on the curve at $496 \mathrm{~nm}$. Radii Cal showed a wavelength of emission between 420 and $520 \mathrm{~nm}$, with an emission peak at $467 \mathrm{~nm}$. Elipar Freelight 2 presented an emission spectrum between 415 and $520 \mathrm{~nm}$, with an emission peak at $454 \mathrm{~nm}$. The wavelength of emission for Bluephase was between 410 and $530 \mathrm{~nm}$, with a peak on the curve at $454 \mathrm{~nm}$.

\section{Degree of Conversion}

The results for DC are shown in Table 2. The factors "bonding agent" $(p<0.001)$ and "LCU" $(p<0.001)$ were

\begin{tabular}{|c|c|c|c|c|}
\hline \multirow[b]{2}{*}{ Bonding Agents } & \multirow{2}{*}{$\begin{array}{c}\text { QTH } \\
\text { Optilux } 501\end{array}$} & \multicolumn{3}{|c|}{ LEDs } \\
\hline & & Radii Cal & Bluephase & Elipar Freelight2 \\
\hline Scotchbond Multi-Purpose & $59.3(1.1)^{A, C}$ & $57.9(0.5)^{A, C}$ & $57.1(0.4)^{A, C}$ & $58.6(0.4)^{A, C}$ \\
\hline Single Bond 2 & $79.9(1.3)^{\mathrm{B}, \mathrm{a}}$ & $84.5(2.1)^{\text {A.a }}$ & $78.9(2.8)^{\mathrm{B}, \mathrm{a}}$ & $78.3(4.0)^{\mathrm{B} . \mathrm{a}}$ \\
\hline Clearfil SE Bond & $74.1(1.4)^{\mathrm{A}, \mathrm{b}}$ & $65.5(0.4)^{\mathrm{B}, \mathrm{b}}$ & $64.8(0.4)^{\mathrm{B}, \mathrm{b}}$ & $64.7(0.5)^{\mathrm{B}, \mathrm{b}}$ \\
\hline Clearfil $\mathrm{S}^{3}$ Bond & $77.1(1.1)^{A, a}$ & $44.4(4.1)^{\mathrm{B}, \mathrm{d}}$ & $45.4(2.7)^{\mathrm{B}, \mathrm{d}}$ & $43.0(0.8)^{B, d}$ \\
\hline
\end{tabular}


significant, as well as their interaction $(p<0.001)$. The power of the test performed for all sources of variation was 1 . Irrespective of the LCU, SB2 generally showed significantly higher DC, compared with the other bonding agents. When cured using the QTH unit, the DC for SB2 $=$ CS3 $>$ CSE $>$ SBMP. On the other hand, for all the LEDs tested, the DC results showed SB2 $>$ CSE $>$ SBMP $>$ CS3. For SB2, the highest DC was observed when the material was cured with Radii Cal $(p<0.001)$, while there were no significant differences among the other LCUs $(p \geq 0.431)$. In contrast, CSE and CS3 showed significantly higher DC when cured using the QTH unit $(p<0.001)$, while for both materials, similar results were observed among the LEDs $(p \geq 0.142)$. For SBMP, no significant differences among the LCUs were detected $(p \geq 0.29)$.

\section{DISCUSSION}

The current results indicate that the LCUs had a material-dependent effect on the DC of the adhesive agents. Thus, the null-hypothesis tested was rejected. According to the manufacturers, all the materials evaluated in this study had CQ as photoinitiator, which absorbs a wide spectrum of wavelengths from $360 \mathrm{~nm}$ to $510 \mathrm{~nm}$, with an absorbance peak at $468 \mathrm{~nm} .{ }^{11}$ For effective photopolymerization, spectral irradiance of the LCU has to overlap as much as possible with the absorption spectrum of the photoinitiator. ${ }^{8,20}$ Despite differences in irradiance levels, the LEDs presented higher irradiance concentrated around $468 \mathrm{~nm}$ than the QTH unit. Thus, one could expect higher DC values for the LEDs. Nonetheless, the self-etch adhesives CSE and CS3 presented significantly higher DC when lightactivated using the QTH source.

One possible explanation for the above results was reported by Chen and others. ${ }^{8}$ The authors showed the absorption peak of CQ decreases as the light continues to shine, and the absorption curve of $\mathrm{CQ}$ is dislocated to $400 \mathrm{~nm}$ in the later stage of the photoactivation process. During photoreaction, the trimethylnorcamphane part of the $\mathrm{CQ}$ structure remains unchanged; this part is probably responsible for the short-wavelength absorption of the CQ molecule. Shifting the absorption peak wavelength of CQ might favor the curing promoted by QTH sources, which have broader emission spectra; the narrow light emitted by first and second generation LEDs may not excite the trimethylnorcamphane part of $\mathrm{CQ}$. However, alteration in the absorption profile of $\mathrm{CQ}$ may occur at long exposure times; hence, it is questionable whether a 20 -second period of light-activation is sufficient for this effect to occur.

Another point to be observed is that the absorption peak of CQ may shift when the molecule is dissolved in water and solvents. ${ }^{21}$ This might have occurred primarily for the hydrophilic adhesive CS3, impairing its polymerization with LCUs presenting narrow spectra. ${ }^{21}$ In addition, hydrophilic bonding agents with higher water concentration tend to present lower DC. ${ }^{22-23}$ For SB2, although the bonding solution is dissolved in ethanol and water, no interference in polymerization was observed. Lower water content and different comonomer polarity ${ }^{21}$ for SB2 may explain this finding not affecting polymerization using the LED units.

No significant differences among the LCUs were observed for the non-solvated SBMP. This finding is probably related to the high viscosity of this adhesive, thus further restricting the mobility of radicals and monomers. Non-solvated adhesives as SBMP and CSE generally present high viscosity due the presence of high molecular weight monomers, mainly Bis-GMA. ${ }^{24}$ Despite the similar viscosity of SBMP and $\mathrm{CSE},{ }^{24}$ the former does not present fillers in its composition, as does the latter, suggesting a higher content of BisGMA for SBMP. ${ }^{24} \mathrm{~A}$ higher content of a dimethacrylate may render this material as having a greater ability to form crosslinks, which may also interfere with further conversion. ${ }^{1}$ Polymer crosslinking reduces the diffusion of reactants at the latter stage of the reaction, causing a rapid onset of reaction-diffusion-controlled termination, ultimately reducing the extent of conversion. ${ }^{25}$ The fact that, irrespective of the irradiance, all LCUs yielded a similar conversion for SBMP, suggests that a DC of around 58\% may reflect the maximum conversion extent for this adhesive under the conditions tested in the current study.

The same light-activation period was used for all materials and LCUs, regardless of their irradiance level. Therefore, different radiant exposures were delivered to the samples. The manufacturers of adhesives systems indicate one specific exposure time for their materials, not taking into account differences among LCUs. Thus, experimental designs using a constant light-activation time are important to more accurately simulate clinical conditions. Despite the differences in irradiance levels, the results for each adhesive agent were generally similar among the LCUs. The LED Radii Cal, however, although having lower irradiance, showed similar and sometimes improved photopolymerization potential, when compared with the other LEDs. This finding might be related to the emission peak of Radii being more consistent with the absorption peak of CQ. In addition, the polymerization potential of both the self-etch adhesives was affected by the narrow LED lights. As both self-etch agents are from Kuraray, it remains unknown whether the presence of other photosensitizer(s) not informed by the manufacturer may explain this finding.

Conversion measurements have been widely used to provide a relative assessment of the quality of dental adhesives and to correlate to their bond strengths. ${ }^{1,3-4,6,26-28}$ However, because DC is known to not provide a com- 
plete characterization of polymer, other analyses should be used to provide a more in-depth assessment of the network structure. ${ }^{1}$ In addition, DC was evaluated five minutes after light-activation and it is assumed that bonding assemblies might be placed approximately at this time under occlusal loads. It is uncertain, though, whether the DC could increase over longer periods, as the literature presents contrasting findings regarding the increase in conversion over the course of time. ${ }^{17,28}$

The polymerization process of adhesive resins is dependent on many factors, such as monomer structure and functionality, ${ }^{1}$ viscosity, ${ }^{1,24}$ temperature ${ }^{24}$ and the presence of solvents. ${ }^{10,22-23,27}$ Thus, the current study did not aim to compare the DC among the bonding agents, but rather the effect of the LCUs for each system. The current results indicate that the impact of QTH and LED lights on the DC of bonding agents was material-dependent. The combination bonding agent $v s$ curing unit had a significant effect on the DC of the adhesives tested. The manufacturers should provide information, such as minimal irradiance and the time required for optimal light-activation of their adhesive systems, taking into account the increasing use of LED lights by clinicians.

\section{CONCLUSIONS}

Within the limitations of the current study, the following conclusions can be drawn:

- The combination bonding agent vs curing unit had a significant effect on the degree of conversion of the adhesives tested;

- The polymerization potential of both self-etch adhesives was affected by the narrow LED lights;

- Despite the lower irradiance level, the LED with an emission peak more centered at $468 \mathrm{~nm}$ showed similar and sometimes improved photopolymerization potential compared to the other LEDs.

\section{Acknowledgement}

The authors thank Dr William C Brandt for his assistance with the spectral analysis.

(Received 1 March 2010; Accepted 20 July 2010)

\section{References}

1. Bae JH, Cho BH, Kim JS, Kim MS, Lee IB, Son HH, Um CM, Kim CK \& Kim OY (2005) Adhesive layer properties as a determinant of dentin bond strength Journal of Biomedical Materials Research Part B: Applied Biomaterials 74(2) 822-828.
2. Dickens SH \& Cho BH (2005) Interpretation of bond failure through conversion and residual solvent measurements and Weibull analyses of flexural and microtensile bond strengths of bonding agents Dental Materials 21(4) 354-364.

3. Kanehira M, Finger WJ, Hoffmann M, Endo T \& Komatsu M (2006) Relationship between degree of polymerization and enamel bonding strength with self-etching adhesives Journal of Adhesive Dentistry 8(4) 211-216.

4. Cadenaro M, Antoniolli F, Sauro S, Tay FR, Di Lenarda R, Prati C, Biasotto M, Contardo L \& Breschi L (2005) Degree of conversion and permeability of dental adhesives European Journal of Oral Sciences 113(6) 525-530.

5. Navarra CO, Cadenaro M, Armstrong SR, Jessop J, Antoniolli F, Sergo V, Di Lenarda R \& Breschi L (2009) Degree of conversion of Filtek Silorane Adhesive System and Clearfil SE Bond within the hybrid and adhesive layer: An in situ Raman analysis Dental Materials 25(9) 11781185.

6. Navarra CO, Cadenaro M, Codan B, Mazzoni A, Sergo V, De Stefano Dorigo E \& Breschi L (2009) Degree of conversion and interfacial nanoleakage expression of three onestep self-etch adhesives European Journal of Oral Sciences 117(4) 463-469.

7. Ye Q, Wang Y, Williams K \& Spencer P (2007) Characterization of photopolymerization of dentin adhesives as a function of light source and irradiance Journal of Biomedical Materials Research Part B: Applied Biomaterials 80(2) 440-446.

8. Chen YC, Ferracane JL \& Prahl SA (2007) Quantum yield of conversion of the photoinitiator camphorquinone Dental Materials 23(6) 655-664.

9. Nomoto R, McCabe JF \& Hirano S (2004) Comparison of halogen, plasma and LED curing units Operative Dentistry 29(3) 287-294.

10. Guo X, Peng Z, Spencer P \& Wang Y (2009) Effect of initiator on photopolymerization of acidic, aqueous dental model adhesives Journal of Biomedical Materials Research. Part A 90(4) 1120-1127.

11. Ilie N \& Hickel R (2008) Can CQ be completely replaced by alternative initiators in dental adhesives? Dental Materials Journal 27(2) 221-228.

12. Jimenez-Planas A, Martin J, Abalos C \& Llamas R (2008) Developments in polymerization lamps Quintessence International 39(2) e74-84.

13. Strydom C (2002) Dental curing lights-maintenance of visible light curing units $S A D J$ J Journal of the South African Dental Association 57(6) 227-233.

14. Leonard DL, Charlton DG, Roberts HW \& Cohen ME (2002) Polymerization efficiency of LED curing lights Journal of Esthetic and Restorative Dentistry 14(5) 286295.

15. Ak AT, Alpoz AR, Bayraktar O \& Ertugrul F (2010) Monomer release from resin based dental materials cured with LED and halogen lights European Journal of Dentistry 4(1) 34-40.

16. Arikawa H, Kanie T, Fujii K, Takahashi H \& Ban S (2008) Effect of inhomogeneity of light from light curing units on the surface hardness of composite resin Dental Materials Journal 27(1) 21-28. 
17. Arrais CA, Pontes FM, Santos LP, Leite ER \& Giannini M (2007) Degree of conversion of adhesive systems light-cured by LED and halogen light Brazilian Dental Journal 18(1) 54-59.

18. Moraes RR, Faria-e-Silva AL, Ogliari FA, Correr-Sobrinho L, Demarco FF \& Piva E (2009) Impact of immediate and delayed light activation on self-polymerization of dualcured dental resin luting agents Acta Biomaterialia 5(6) 2095-2100.

19. Rueggeberg FA, Hashinger DT \& Fairhurst CW (1990) Calibration of FTIR conversion analysis of contemporary dental resin composites Dental Materials 6(4) 241-249.

20. Neumann MG, Miranda WG, Jr, Schmitt CC, Rueggeberg FA \& Correa IC (2005) Molar extinction coefficients and the photon absorption efficiency of dental photoinitiators and light curing units Journal of Dentistry 33(6) 525-532.

21. Moss L, Rueggeberg FA \& Stansbury JW (2002) Effect of solvent type on absorption profile of camphoroquinone Journal of Dental Research 81(Special Issue) Abstract \#1969 1255.

22. Cadenaro M, Antoniolli F, Codan B, Agee K, Tay FR, Dorigo ED, Pashley DH \& Breschi L (2010) Influence of different initiators on the degree of conversion of experimental adhesive blends in relation to their hydrophilicity and solvent content Dental Materials 26(4) 288-294.

23. Cadenaro M, Breschi L, Antoniolli F, Navarra CO, Mazzoni A, Tay FR, Di Lenarda R \& Pashley DH (2008) Degree of conversion of resin blends in relation to ethanol content and hydrophilicity Dental Materials 24(9) 1194-1200.
24. Faria-e-Silva AL, Piva E \& Moraes RR (2010) Time-dependent effect of refrigeration on viscosity and conversion kinetics of dental adhesive resins European Journal of Dentistry 4(2) $150-155$.

25. Sideridou I, Tserki V \& Papanastasiou G (2002) Effect of chemical structure on degree of conversion in light-cured dimethacrylate-based dental resins Biomaterials 23(8) 1819-1829.

26. Kim JS, Choi YH, Cho BH, Son HH, Lee IB, Um CM \& Kim CK (2006) Effect of light-cure time of adhesive resin on the thickness of the oxygen-inhibited layer and the microtensile bond strength to dentin Journal of Biomedical Materials Research Part B: Applied Biomaterials 78(1) 115123.

27. Klein-Junior CA, Zander-Grande C, Amaral R, Stanislawczuk R, Garcia EJ, Baumhardt-Neto R, Meier MM, Loguercio AD \& Reis A (2008) Evaporating solvents with a warm air-stream: Effects on adhesive layer properties and resin-dentin bond strengths Journal of Dentistry 36(8) 618-625.

28. Sadek FT, Calheiros FC, Cardoso PE, Kawano Y, Tay F \& Ferrari M (2008) Early and 24-hour bond strength and degree of conversion of etch-and-rinse and self-etch adhesives American Journal of Dentistry 21(1) 30-34. 